\title{
Neocentric small supernumerary marker chromosomes (SSMC) - three more cases and review of the literature
}

\author{
T. Liehr ${ }^{\mathrm{a}} \quad$ G.E. Utine ${ }^{\mathrm{b}} \quad$ U. Trautmann ${ }^{\mathrm{c}} \quad$ A. Rauch ${ }^{c} \quad$ A. Kuechler ${ }^{\mathrm{a}, \mathrm{d}} \quad$ J. Pietrzak $^{\mathrm{e}}$

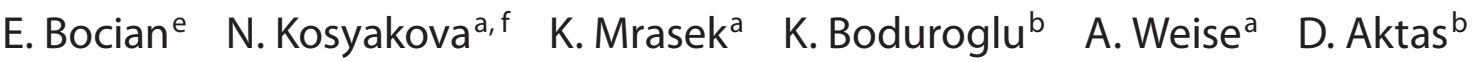 \\ a Institute of Human Genetics and Anthropology, Jena (Germany) \\ ${ }^{b}$ Hacettepe University Faculty of Medicine, Department of Genetics, Ankara (Turkey) \\ ${ }^{\mathrm{c}}$ Institute of Human Genetics, Erlangen; ${ }^{\mathrm{d}}$ Department of Pediatrics, Jena (Germany) \\ ${ }^{\mathrm{e}}$ Department of Medical Genetics, Institute of Mother and Child, Warsaw (Poland) \\ ${ }^{\mathrm{f}}$ Research Centre for Medical Genetics, Moscow (Russia)
}

The author's name J. Pietrzak was misspelled. 